Check for updates

Cite this: Chem. Commun., 2018, 54, 9953

Received 20th June 2018, Accepted 3rd August 2018

DOI: $10.1039 / \mathrm{c} 8 \mathrm{cc} 04919 j$

rsc.li/chemcomm

\section{ESIPT-based ratiometric fluorescence probe for the intracellular imaging of peroxynitrite $\dagger$}

\author{
Luling Wu, (D) $\ddagger^{\mathrm{a}}$ Yang Wang, $\ddagger^{\mathrm{b}}$ Maria Weber, (D) ${ }^{\mathrm{a}}$ Liyuan Liu, ${ }^{\mathrm{a}}$ \\ Adam C. Sedgwick, (D) *a Steven D. Bull, (D) *a Chusen Huang (D)*b and \\ Tony D. James (D) *ac
}

In this work, we set out to develop an endoplasmic reticulum (ER) directed ESIPT-based $\mathrm{ONOO}^{-}$ratiometric fluorescent probe (ABAH-LW). ABAH-LW was synthesized in four steps and found to have a high sensitivity and selectivity towards the detection of $\mathrm{ONOO}^{-}$. ABAH-LW was able to detect low concentrations of ONOO $^{-}$(limit of detection $=21.4 \mathrm{nM}$ ) within seconds producing a ratiometric change in fluorescence intensity. ABAH-LW further demonstrated the ability to ratiometrically image endogenous and exogenous $\mathrm{ONOO}^{-}$in HeLa cells. Moreover, co-localization experiments were carried out using commercially available ER-Tracker Red, Lyso-Tracker Red and Mito-Tracker-Red, which were co-stained with ABAH-LW in HeLa cells. For ER-Tracker Red, Pearson's correlation co-efficient of 0.93 was determined and 3D surface plot analysis illustrated a large overlap between ABAH-LW and ER-Tracker Red using both red and blue channels. In addition some co-localisation with Mito-Tracker Red and ABAH-LW was observed (0.73).

The endoplasmic reticulum (ER) is a large membrane network that plays a central role in eukaryotic cells as a 'protein-folding factory' including being responsible for the synthesis, maturation and trafficking of a wide range of proteins. ${ }^{1,2}$ In addition, the ER is also an important site for calcium $\left(\mathrm{Ca}^{2+}\right)$ storage and homeostasis. ${ }^{3}$ However, the ER is known to be sensitive to environmental and physiological changes such as inflammatory stimuli, change in $\mathrm{Ca}^{2+}$ levels, nutrient levels and increase in protein synthesis. ${ }^{2}$ These changes to the cellular environment

\footnotetext{
${ }^{a}$ Department of Chemistry, University of Bath, Bath, BA2 7AY, UK.

E-mail:t.d.james@bath.ac.uk,s.d.bull@bath.ac.uk, a.c.sedgwick@bath.ac.uk

${ }^{b}$ The Education Ministry Key Laboratory of Resource Chemistry, Shanghai Key

Laboratory of Rare Earth Functional Materials, and Shanghai Municipal Education Committee Key Laboratory of Molecular Imaging Probes and Sensors, Department of Chemistry, Shanghai Normal University, 100 Guilin Road, Shanghai 200234, China. E-mail: huangcs@shnu.edu.cn

${ }^{c}$ Department of Materials and Life Sciences, Faculty of Science and Technology,

Sophia University, 7-1 Kioi-cho, Chiyoda-ku, Tokyo 102-8554, Japan

$\dagger$ Electronic supplementary information (ESI) available. See DOI: 10.1039/ c8cc04919j

\$ Equal contributions.
}

result in an accumulation of unfolded or misfolded proteins, this accumulation is known as ER stress. To prevent the accumulation of unfolded or misfolded proteins, eukaryotic cells have developed an unfolded protein response (UPR). It is believed that both UPR and ER stress are involved in the pathology of several diseases including cancer, neurodegenerative diseases and atherosclerosis.

Peroxynitrite $\left(\mathrm{ONOO}^{-}\right)$is a highly reactive nitrogen species, which acts as a signaling molecule in vivo for a number of pathways. ${ }^{4,5}$ However, $\mathrm{ONOO}^{-}$is more commonly known for its deleterious effects, causing irreversible damage to a range of biological targets such as lipids, proteins and DNA. ${ }^{6}$ In addition, $\mathrm{ONOO}^{-}$has been shown to induce ER stress by depleting $\mathrm{ER} \mathrm{Ca}^{2+}$ levels and elevating cytosolic $\mathrm{Ca}^{2+}$ levels resulting in the promotion of apoptosis. Additionally, biomarkers of ER stress were found to co-localize with 3-nitrotyrosine-containing proteins $\left(\mathrm{ONOO}^{-}\right.$indicator) within early atherosclerotic lesions, which suggests that $\mathrm{ONOO}^{-}$contributes to atherogenesis via ER stress. ${ }^{7}$ Therefore, the development of powerful tools for the real-time detection of $\mathrm{ONOO}^{-}$at the endoplasmic reticulum would further aid the understanding of the role of $\mathrm{ONOO}^{-}$in ER-related diseases.

Within our research, we are particularly interested in the development of small molecule fluorescent probes for the detection of biologically relevant analytes in vivo owing to their high sensitivity, selectivity, high spatial and temporal resolution..$^{8-12}$ Currently, there are several targeted fluorescence probes for the detection of biologically relevant analytes. However, to the best of our knowledge, there are no $\mathrm{ONOO}^{-}$fluorescence probes that localize at the ER so we set out to develop an ER-targeting $\mathrm{ONOO}^{-}$fluorescence probe. ${ }^{13-16}$

Excited-state intramolecular proton transfer (ESIPT) fluorescence probes are emerging in the literature owing to several particularly attractive properties such as: a large Stokes shift $(\sim 200 \mathrm{~nm})$ and spectral sensitivity to the surrounding environment. More importantly, ESIPT enables ratiometric detection of its target analyte due to the emission of the enol and keto forms (Dual-emission) (Scheme S2, ESI $\dagger$ ). The use of Ratiometric 
(a)<smiles>Nc1ccc(O)c(-c2nc3ccccc3s2)c1</smiles>

(b)

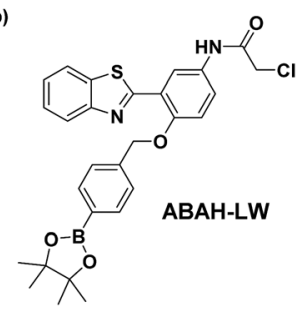

Fig. 1 (a) ABAH ESIPT fluorophore previously used in the literature (b) this work - dual functionalised $\mathrm{ABAH}$ for the imaging of $\mathrm{ONOO}^{-}$at the ER.

fluorescence probes are particularly valuable as they provide direct information about the concentration of the target analyte without the need for calibration.

We identified in the literature an ESIPT fluorophore 4-amino-2-(benzo[d]thiazol-2-yl)phenol fluorophore (ABAH) ${ }^{17-21}$ as an ideal scaffold for the development of an ER targeted $\mathrm{ONOO}^{-}$fluorescence probe ABAH-LW (Fig. 1).

It was believed the attachment of the benzyl boronic ester to the phenol of ABAH would block the ESIPT process resulting in only enol emission being observed. Due to boronates/ boronic acids having a greater reactivity towards $\mathrm{ONOO}^{-}$over $\mathrm{HClO} / \mathrm{ClO}^{-}$(min) and $\mathrm{H}_{2} \mathrm{O}_{2}$ (hours), this unit would therefore allow the selective detection of $\mathrm{ONOO}^{-8,10,11,22}$ Furthermore, the functionalization of the amino group of $\mathbf{A B A H}$ with a thiolreactive chloroacetamide functional group enables the covalent attachment of ABAH-LW to biomacromolecules located at the ER enabling targeted visualization of the ER in the presence of $\mathrm{ONOO}^{-} .^{23}$

ABAH-LW was synthesized over four steps. ABAH was first synthesized in excellent yield (73\%) by heating 2-aminophenol and $p$-aminosalicylic acid in polyphosphoric acid (PPA) at $180{ }^{\circ} \mathrm{C}$. With ABAH in hand, chloroacetylchloride was then added to a solution of ABAH in $1: 1 \mathrm{CHCl}_{3} / \mathrm{CH}_{3} \mathrm{CN}$. This reaction proceeded quickly to afford chloroacetamide intermediate compound $\mathbf{2}$. Compound 2 was then alkylated using (4-bromomethylphenyl)boronic acid and $\mathrm{K}_{2} \mathrm{CO}_{3}$ in DMF to afford ABAH-LW in $25 \%$ yield (Scheme S1, ESI $\dagger$ ). Upon isolating ABAH-LW, we initially evaluated changes in the UV-vis spectrum of ABAH-LW with and without $\mathrm{ONOO}^{-}$. With the addition of $\mathrm{ONOO}^{-}(8 \mu \mathrm{M})$, an increase in absorption was observed at $340 \mathrm{~nm}$ (see $\mathrm{ESI}^{\dagger}$, Fig. S2). We then turned our attention towards the ability of ABAH-LW to detect $\mathrm{ONOO}^{-}$by fluorescence. It has been previously reported that the fluorescence emission of the ESIPT process can be affected by intermolecular hydrogen bonding. ${ }^{24}$ Therefore, for the fluorescence experiments of ABAH-LW with $\mathrm{ONOO}^{-}$the experiments were carried out in PBS buffer ( $\mathrm{pH} 8.2$, containing 8\% DMSO, $1 \mathrm{mM} \mathrm{CTAB}$ ) at room temperature.

As shown in Fig. 2, only the enol emission peak at $405 \mathrm{~nm}$ of ABAH-LW was observed, since the ESIPT process is blocked by the benzyl boronic ester. However, addition of $\mathrm{ONOO}^{-}(0-10 \mu \mathrm{M})$, resulted in a ratiometric fluorescence intensity change, with a decrease in enol emission intensity at $405 \mathrm{~nm}$ and increase in keto emission intensity at $481 \mathrm{~nm}$. The addition of $\mathrm{ONOO}^{-}(9 \mu \mathrm{M})$ led to a significant 103-fold increase in ratiometric fluorescence intensity $\left(F_{481} / F_{405}\right)$. The $\mathrm{ONOO}^{-}$deprotection and release of the

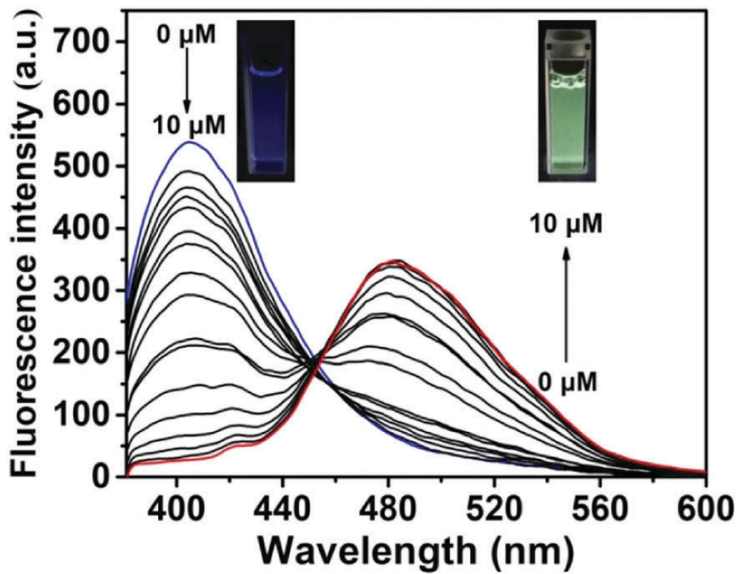

Fig. 2 Changes in fluorescence emission of ABAH-LW $(3 \mu \mathrm{M})$ with increasing addition of $\mathrm{ONOO}^{-}$(from 0 to $10 \mu \mathrm{M}$ ) in PBS buffer (pH 8.2, containing $8 \%$ DMSO, $1 \mathrm{mM}$ CTAB) after $1 \mathrm{~min}$. $\lambda_{\mathrm{ex}}=370 \mathrm{~nm}$. Slit widths: $\mathrm{ex}=5 \mathrm{~nm}, \mathrm{em}=6 \mathrm{~nm}$.

ESIPT fluorophore was further confirmed using mass spectrometry (see ESI $\dagger$, Fig. S1). In addition, the change in the fluorescence emission of the test solution was confirmed using a UV lamp (365 nm) a change from blue to bright green in colour was observed (Fig. 2, inset). ABAH-LW was shown to be very sensitive towards $\mathrm{ONOO}^{-}$with a detection limit of $21.4 \mathrm{nM}$.

The selectivity of ABAH-LW towards other ROS and biologically relevant analytes was performed. As illustrated in Fig. 3, ABAH-LW exhibited excellent selectivity for $\mathrm{ONOO}^{-}$over other ROS including $\mathrm{H}_{2} \mathrm{O}_{2}$ and $\mathrm{HClO} / \mathrm{ClO}^{-}$. Moreover, no change in fluorescence intensity was observed for the addition of various metal ions and amino acids. This excellent selectivity enabled us to evaluate ABAH-LW for cellular imaging in the detection of $\mathrm{ONOO}^{-}$and its ability to localize at the ER.

ABAH-LW $(50 \mu \mathrm{M})$ was incubated with HeLa cells and was cell permeable with only blue emission (Fig. 4a). As shown

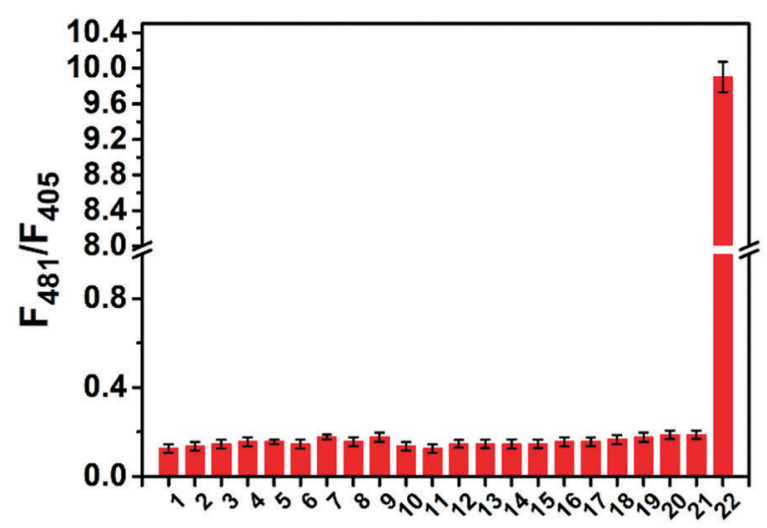

Fig. 3 Fluorescence intensity ratio changes (based on the peak heights at the maxima, 405 and $481 \mathrm{~nm}$ respectively) with addition of $\mathrm{ONOO}^{-}(8 \mu \mathrm{M})$ and other interfering reagents $(100 \mu \mathrm{M})$. 1. probe only, 2. $\mathrm{ClO}^{-} ; 3 . \mathrm{H}_{2} \mathrm{O}_{2}$; 4. $\mathrm{NO} ; 5 . \cdot \mathrm{OH}^{2}$ 6. $\cdot \mathrm{O}^{2-} ; 7 .{ }^{1} \mathrm{O}_{2} ; 8 . \mathrm{H}_{2} \mathrm{~S} ; 9$. glucose; $10 . \mathrm{GSH} ; 11 . \mathrm{Cys} ; 12 . \mathrm{Hcy}$; 13. $\mathrm{Na}^{+} ; 14 . \mathrm{K}^{+} ; 15 . \mathrm{Ca}^{2+} ; 16 . \mathrm{Mg}^{2+} ; 17 . \mathrm{Zn}^{2+} ; 18 . \mathrm{Fe}^{2+} ; 19 . \mathrm{Al}^{3+} 20 . \mathrm{Cu}^{2+}$; 21. $\mathrm{Fe}^{3+} ; 22 . \mathrm{ONOO}^{-} . \lambda_{\mathrm{ex}}=370 \mathrm{~nm}$. Error bar represents s.d. Slit widths: ex $=5 \mathrm{~nm}$, em $=6 \mathrm{~nm}$. $40 \mathrm{~min}$ wait between measurements. 


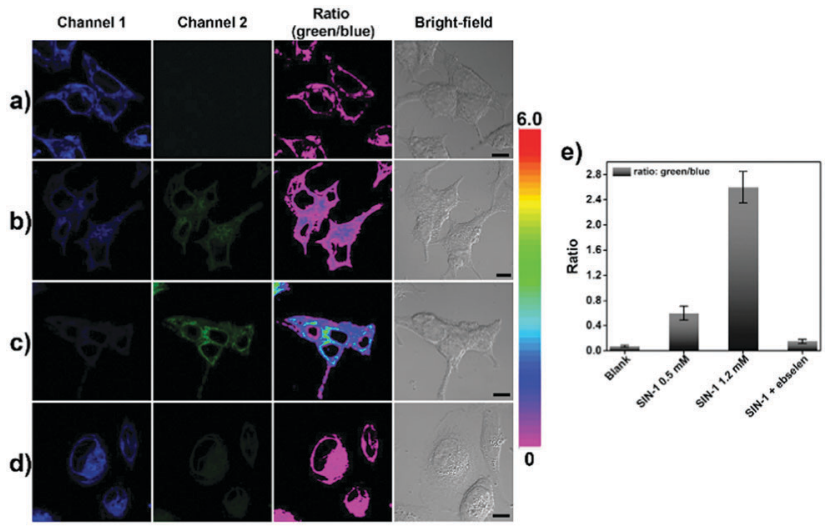

Fig. 4 Confocal fluorescence imaging of ABAH-LW with exogenous addition of $\mathrm{ONOO}^{-}$donor (SIN-1) in HeLa cells. HeLa cells were incubated with ABAH-LW (50 $\mu \mathrm{M}$ ) then (a) 0, (b) 0.5, (c) $1.2 \mathrm{mM} \mathrm{SIN-1} \mathrm{and} \mathrm{(d)} 200 \mu \mathrm{M}$ ebselen and $1.2 \mathrm{mM}$ SIN-1. Channel 1 (blue, 410-460 nm); channel 2 (green, 480-550 nm). Ratio images generated from green/blue channel. (e) Average intensity ratios from ratio images of a-d. $\lambda_{\text {ex }}=405 \mathrm{~nm}$, scale bar: $10 \mu \mathrm{m}$.

in Fig. $4 \mathrm{~b}$ and $\mathrm{c}$, the addition of $\mathrm{SIN}^{-1}{ }^{25}\left(\mathrm{ONOO}^{-}\right.$donor) 0.5 and $1.2 \mathrm{mM}$ led to a ratiometric change in fluorescence intensity. A concentration dependent change of fluorescence emission intensity with SIN-1 was observed. The exogenous addition of $1.2 \mathrm{mM}$ (SIN-1) gave the largest ratiometric change with low blue emission fluorescence intensity being observed in channel 1 and high green emission intensity being observed in channel 2. The addition of the $\mathrm{ONOO}^{-}$scavenger ebselen $(200 \mu \mathrm{M})$ led to no ratiometric change in fluorescence intensity with the addition of SIN-1 (1.2 mM) (Fig. 4d). This indicates the requirement of $\mathrm{ONOO}^{-}$to produce a ratiometric change in fluorescence intensity.

Lipopolysaccharide (LPS) and Interferon- $\gamma$ (IFN- $\gamma$ ) was then used to produce endogenous $\mathrm{ONOO}^{-}$by stimulating the production of ROS/RNS in HeLa cells. As displayed in Fig. 5, a large ratiometric change in fluorescence intensity was observed. Ebselen was then added in the presence of LPS and IFN- $\gamma$ and as expected no change in fluorescence was observed (Fig. $5 \mathrm{c}$ ).

To determine the sub-cellular distribution of ABAH-LW at the ER, co-localization experiments were performed. Commercially available ER-Tracker Red, Lyso-Tracker Red and Mito-Tracker Red were co-stained with ABAH-LW in HeLa cells (Fig. 6a, b and Fig. S6-S8, ESI $\dagger$ ). The Pearson's correlation coefficient with ER-Tracker Red was determined as 0.93. In comparison, the Pearson's correlation coefficient was determined as 0.43 and 0.73 with Lyso-Tracker Red and Mito-Tracker Red respectively therefore indicating the selectivity of ABAH-LW for the localization at the ER. Furthermore, the linear region of interest (ROI) indicated by the white line (Fig. 6) shows significant overlap between the fluorescence intensities of ABAH-LW and ER-Tracker Red over the set distance (Fig. 6d). Moreover, the 3D surface plot analysis qualitatively demonstrates the co-localization of ER-Tracker Red and ABAH-LW since both have an increased intensity in the ROI (Fig. 6c, e, f). Therefore, ABAH-LW demonstrates greater selectivity for the labelling of the ER. However,

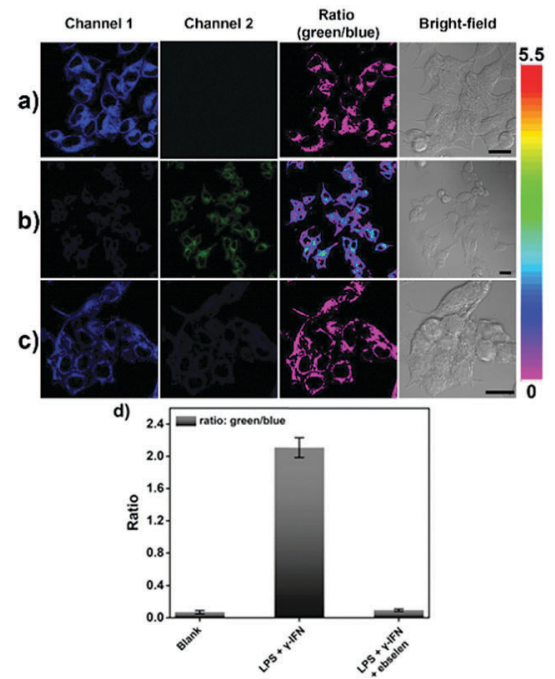

Fig. 5 Fluorescence imaging of peroxynitrite in HeLa cells treated with (a) no, (b) $1.2 \mu \mathrm{g} \mathrm{mL}^{-1}$ LPS $16 \mathrm{~h}, 70 \mathrm{ng} \mathrm{mL}^{-1}$ IFN $-\gamma 4 \mathrm{~h}$, (c) LPS, IFN- $\gamma+150 \mu \mathrm{M}$ ebselen. (d) Average intensity ratios from ratio images of a-c. The cells were stained with $50 \mu \mathrm{M}$ ABAH-LW $(50 \mu \mathrm{M})$ for $30 \mathrm{~min}$ and washed with DPBS and imaged by confocal microscopy. Channel 1 (blue, 410-460 nm); channel 2 (green, $480-550 \mathrm{~nm}$ ). $\lambda_{\mathrm{ex}}=405 \mathrm{~nm}$, scale bar: $20 \mu \mathrm{m}$.

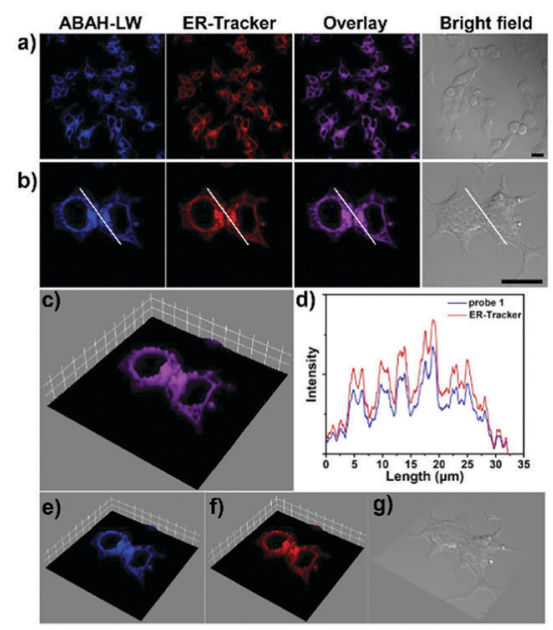

Fig. 6 Endoplasmic reticulum-targeting properties of ABAH-LW in HeLa cells at $37{ }^{\circ} \mathrm{C}$. (a and b) Colocalization images of HeLa cells stained with ER-Tracker Red $\left(1 \mu \mathrm{M}\right.$, red channel, $\left.\lambda_{\mathrm{ex}}=568 \mathrm{~nm}, \lambda_{\mathrm{em}}=575-675 \mathrm{~nm}\right)$ and ABAH-LW $\left(50 \mu \mathrm{M}\right.$, blue channel, $\left.\lambda_{\mathrm{ex}}=405 \mathrm{~nm}, \lambda_{\mathrm{em}}=410-460 \mathrm{~nm}\right)$ scale bar: $20 \mu \mathrm{m}$. (d) Intensity profiles within the ROI (regions of interest, white line in b) of ABAH-LW and ER-Tracker Red across HeLa cells. (c and e-g) 3D surface plot analyzing the colocalization images of ABAH-LW and ER-Tracker co-stained HeLa cells using interactive 3D surface plots in ImageJ software.

co-localisation of Mito-Tracker Red and ABAH-LW was also observed (0.73), which is due to similar reactive thiol units being present at the mitochondria. ${ }^{26,27}$

An ESIPT-based $\mathrm{ONOO}^{-}$ratiometric fluorescence probe (ABAH-LW) was synthesized in four steps. ABAH-LW was found to have a high sensitivity and selectivity towards the detection of $\mathrm{ONOO}^{-}$. ABAH-LW was able to detect low concentrations of $\mathrm{ONOO}^{-}$(limit of detection $=21.4 \mathrm{nM}$ ) within seconds 
producing a ratiometric change in fluorescence intensity. ABAH-LW was able to ratiometrically image endogenous and exogenous $\mathrm{ONOO}^{-}$in HeLa cells. Co-localization experiments were carried out using ER-Tracker Red, which produced a Pearson's correlation co-efficient of 0.93 whereas values 0.43 and 0.73 were observed for Lyso-Tracker Red and Mito-Tracker Red. In summary ABAH-LW exhibits great promise as a tool for the intracellular imaging of $\mathrm{ONOO}^{-}$in cells. Since, ABAH-LW displays excellent selectivity for the ER (Pearson's correlation co-efficient of 0.93 with ER-Tracker Red). However, we are currently working on improving the targeting of ABAH-LW for the ER given that some targeting of mitochondria was observed (Pearson's correlation co-efficient of 0.73 with Mito-Tracker Red).

LW wishes to thank China Scholarship Council and the University of Bath for supporting his PhD work in the UK. We would like to thank the EPSRC and the University of Bath for funding. ACS thanks the EPSRC for a studentship. $\mathrm{CH}$ would like to thank the National Natural Science Foundation of China (Grants 21672150, and 213021125), Shanghai "Chenguang" Program (Grant 14CG42), and Program for Changjiang Scholars and Innovative (IRT_16R49). TDJ wishes to thank the Royal Society for a Wolfson Research Merit Award and Sophia University for a visiting professorship. NMR characterisation facilities were provided through the Chemical Characterisation and Analysis Facility (CCAF) at the University of Bath (www.bath.ac.uk/ccaf). The EPSRC UK National Mass Spectrometry Facility at Swansea University is thanked for analyses. All data supporting this study are provided as supplementary information accompanying this paper $(\mathrm{ESI} \dagger)$.

\section{Conflicts of interest}

No conflicts of interest.

\section{Notes and references}

1 K. Z. Zhang and R. J. Kaufman, Nature, 2008, 454, 455-462. 2 M. Wang and R. J. Kaufman, Nat. Rev. Cancer, 2014, 14, 581-597.
3 K. Zhang and R. J. Kaufman, Nature, 2008, 454, 455.

4 P. Pacher, J. S. Beckman and L. Liaudet, Physiol. Rev., 2007, 87, 315-424.

5 S. Csaba, I. Harry and R. Rafael, Nat. Rev. Drug Discovery, 2007, 6, 662.

6 P. Ascenzi, A. di Masi, C. Sciorati and E. Clementi, BioFactors, 2010, 36, 264-273.

7 J. G. Dickhout, G. S. Hossain, L. M. Pozza, J. Zhou, S. Lhotak and R. C. Austin, Arterioscler., Thromb., Vasc. Biol., 2005, 25, 2623-2629.

8 A. C. Sedgwick, H. H. Han, J. E. Gardiner, S. D. Bull, X. P. He and T. D. James, Chem. Commun., 2017, 53, 12822-12825.

9 A. C. Sedgwick, R. S. L. Chapman, J. E. Gardiner, L. R. Peacock, G. Kim, J. Yoon, S. D. Bull and T. D. James, Chem. Commun., 2017, 53, 10441-10443.

10 A. C. Sedgwick, H. H. Han, J. E. Gardiner, S. D. Bull, X. P. He and T. D. James, Chem. Sci., 2018, 9, 3672-3676.

11 A. C. Sedgwick, X. L. Sun, G. Kim, J. Yoon, S. D. Bull and T. D. James, Chem. Commun., 2016, 52, 12350-12352.

12 D. Wu, A. C. Sedgwick, T. Gunnlaugsson, E. U. Akkaya, J. Yoon and T. D. James, Chem. Soc. Rev., 2017, 46, 7105-7123.

13 Y. H. Tang, A. Xu, Y. Y. Ma, G. P. Xu, S. Y. Gao and W. Y. Lin, Sci. Rep., 2017, 7.

14 H. B. Xiao, C. C. Wu, P. Li and T. G. Bo, Anal. Chem., 2018, 90, 6081-6088.

15 H. B. Xiao, X. Liu, C. C. Wu, Y. H. Wu, P. Li, X. M. Guo and B. Tang, Biosens. Bioelectron., 2017, 91, 449-455.

16 F. Ali, S. Sreedharan, A. H. Ashoka, H. K. Saeed, C. G. W. Smythe, J. A. Thomas and A. Das, Anal. Chem., 2017, 89, 12087-12093.

17 K. S. Hwang, K. Y. Park, D. B. Kim and S.-K. Chang, Dyes Pigm., 2017, 147, 413-419.

18 Y. Zhao, Y. Xue, H. Li, R. Zhu, Y. Ren, Q. Shi, S. Wang and W. Guo, Spectrochim. Acta, Part A, 2017, 175, 215-221.

19 H. Yao and T. Funada, Chem. Commun., 2014, 50, 2748-2750.

20 L. Cui, W. Zhu, Y. Xu and X. Qian, Anal. Chim. Acta, 2013, 786, 139-145.

21 M. Santra, B. Roy and K. H. Ahn, Org. Lett., 2011, 13, 3422-3425.

22 A. Sikora, J. Zielonka, M. Lopez, J. Joseph and B. Kalyanaraman, Free Radical Biol. Med., 2009, 47, 1401-1407.

23 S. Arai, S. C. Lee, D. T. Zhai, M. Suzuki and Y. T. Chang, Sci. Rep., 2014, 4.

24 N. Sarkar, K. Das, S. Das, A. Datta, D. Nath and K. Bhattacharyya, J. Phys. Chem., 1995, 99, 17711-17714.

25 F. J. Martin-Romero, Y. Gutierrez-Martin, F. Henao and C. GutierrezMerino, J. Fluoresc., 2004, 14, 17-23.

26 A. D. Presley, K. M. Fuller and E. A. Arriaga, J. Chromatogr. B: Anal. Technol. Biomed. Life Sci., 2003, 793, 141-150.

27 M. H. Lee, N. Park, C. Yi, J. H. Han, J. H. Hong, K. P. Kim, D. H. Kang, J. L. Sessler, C. Kang and J. S. Kim, J. Am. Chem. Soc., 2014, 136, 14136-14142. 